\title{
BMJ Open Sex differences in prevalence and determinants of hypertension among adults: a cross-sectional survey of one rural village in Bangladesh
}

\author{
Jessica Yasmine Islam (D) , 1,2 M Mostafa Zaman, ${ }^{1}$ Jasim Uddin Ahmed, ${ }^{3}$ \\ Sohel Reza Choudhury, ${ }^{1,4}$ Hasanuzzaman Khan (D) , ${ }^{1}$ Tashfin Zissan ${ }^{1}$
}

To cite: Islam JY, Zaman MM, Ahmed JU, et al. Sex differences in prevalence and determinants of hypertension among adults: a cross-sectional survey of one rural village in Bangladesh. BMJ Open 2020;10:e037546. doi:10.1136/ bmjopen-2020-037546

- Prepublication history for this paper is available online. To view these files, please visit the journal online (http://dx.doi org/10.1136/bmjopen-2020037546).

Received 07 February 2020 Revised 12 May 2020 Accepted 24 July 2020

Check for updates

(c) Author(s) (or their employer(s)) 2020. Re-use permitted under CC BY-NC. No commercial re-use. See rights and permissions. Published by BMJ.

${ }^{1}$ Department of Primary Care, Ekhlaspur Center of Health, Chandpur, Bangladesh ${ }^{2}$ Department of Epidemiology, UNC Gillings School of Global Public Health, Chapel Hill, NC, United States

${ }^{3}$ Tobacco Control, Ekhlaspur Center of Health, Chandpur, Bangladesh

${ }^{4}$ Department of Epidemiology \& Research, National Heart Foundation Hospital \& Research Institute, Dhaka, Bangladesh

Correspondence to Dr Jessica Yasmine Islam; islamjy@email.unc.edu

\section{ABSTRACT}

Objective Prevention of mortality due to cardiovascular disease (CVD) through control of hypertension is a public health priority in Bangladesh. Our objective was to assess sex differences in prevalence and determinants of hypertension among adults in one rural area of Bangladesh.

Study design Cross-sectional.

Setting and participants From January 2014 to

December 2015, we conducted a cross-sectional study of 2600 men and women aged $\geq 18$ years located in one rural district of Bangladesh. We collected data on demographics, behavioural factors, physical measurements and health history.

Primary outcome measures Our primary outcome was hypertension (systolic blood pressure $\geq 140$ or diastolic blood pressure $\geq 90 \mathrm{~mm} \mathrm{Hg}$ ).

Results The average age of participants was 41.6 years and $53.7 \%$ were women. Hypertension prevalence was $6.9 \%$ (95\% Cl 5.9 to 7.9 ), and was significantly higher among women (8.9\%) than men (4.5\%). The highest prevalence of hypertension was observed among women aged $\geq 60$ years at $21.3 \%(95 \% \mathrm{Cl} 16.6$ to 26.7$)$. A higher proportion of men with hypertension were aware of their condition (72.2\%) compared with women (52.4\%). Determinants of hypertension included older age, higher education, current tobacco use, increasing body mass index, and hyperglycaemia.

Conclusion Our research suggests that hypertension prevalence is higher among women than men in rural Bangladesh. Sex-specific interventions should be developed to inform adults of the necessary lifestyle changes that may reduce the risk of hypertension and subsequent CVDs.

\section{INTRODUCTION}

Globally, hypertension, also known as high or raised blood pressure, is a leading cause of disease burden and mortality. ${ }^{1}$ Hypertension contributes to the burden of cardiovascular disease (CVDs), stroke and kidney failure, and disproportionately affects populations living in low/middle-income countries (LMICs). Hypertension is a preventable
Strengths and limitations of this study

- The population studied was enumerated by the Ekhlaspur Center of Health (ECOH) study staff, which allowed us to provide accurate estimates of prevalence using a well-defined denominator in a rural area of Bangladesh.

- We used WHO-recommended standardised methods to measure blood pressure to limit the potential for measurement error.

- Generalisability of our results may be limited as community-level campaigns commonly took place in this village covering topics on non-communicable disease prevention and lifestyle changes that may reduce their risk of developing chronic diseases .

- Self-reported medication use may be subject to social desirability bias as participants are in regular contact with $\mathrm{ECOH}$ staff members through community campaigns and prior surveillance efforts.

- We were unable to measure important risk factors of hypertension such as diet, physical activity, waist circumference, family history of cardiovascular disease and blood lipid levels.

condition through healthy diet, normal body mass index, controlled salt intake, and physical activity. ${ }^{1}$ When diagnosed at an early stage, hypertension can be successfully controlled through appropriate treatment and successful control through lifestyle changes. ${ }^{1}$ However, the burden and mortality due to hypertension is growing globally, particularly in LMICs, ${ }^{1-3}$ where access to preventive services and treatment is limited. In Bangladesh, the prevalence of hypertension among adults has been increasing for the past several decades, ${ }^{4}$ rising from $\sim 10 \%$ in the $90 \mathrm{~s}^{5}$ to $20 \%$ based on estimates published by the World Health Organization (WHO) ${ }^{6}$ As such, prevention and control of hypertension is a growing public health concern and a priority of Bangladesh's public health agenda. ${ }^{78}$ 
Although $70 \%$ of the population of Bangladesh resides in rural areas, few prior studies have investigated the burden and determinants of hypertension among adults in rural areas. ${ }^{9-11}$ Additionally, prior studies conducted in Bangladesh to assess risk factors of non-communicable diseases (NCDs), including hypertension, have concluded that the majority of the NCD burden lies in urban areas among individuals with high socioeconomic status. ${ }^{12}$ This finding implies the epidemiological shift to a higher burden of chronic disease is of major concern in urban regions of the country rather than rural areas of Bangladesh. ${ }^{9}$ However, high-risk groups in rural areas should be identified and provided with tailored prevention programmes, such as sex-specific interventions. One recent study conducted to assess risk factors of NCDs among a sample of over 12000 rural residents aged $\geq 30$ years found that the prevalence of hypertension was $15.9 \%$ among men and $22.5 \%$ among women. ${ }^{11}$ This finding indicates a significant difference in burden among rural men and women, with women's prevalence approaching the overall prevalence of adults residing in urban areas of Bangladesh. ${ }^{9}{ }^{13}$ Data are needed to assess determinants of high blood pressure among women in rural areas and identify any sex-based disparities on hypertension medication use. Our objective was to evaluate differences in prevalence and associated determinants of hypertension and prehypertension in a rural area of Bangladesh. Additionally, we assessed self-reported antihypertensive medication use among our adult and rural study population.

\section{METHODS}

Data for this analysis were collected from January 2014 to December 2015 among residents, aged 18 years or older, in a rural area of Bangladesh named, Ekhlaspur village of Matlab North subdistrict. Ekhlaspur is located about $60 \mathrm{~km}$ south-east of Dhaka city, the capital of Bangladesh. Ekhlaspur Center of Health (ECOH), a local nongovernmental health promotion organisation, conducts periodic demographic surveys in the village. ${ }^{14} \mathrm{ECOH}$ was founded in 1999 (by MMZ) but it has been managed and funded by the local community.

Data included in this analysis were obtained through ECOH's routine surveillance work and biennial health check-up of all adult residents of the village. To inform the community about this survey, ECOH management organised meetings and orientations with the community leaders, schools and union council members. This survey is part of the community's initiative to monitor their health status and to detect any hypertension, diabetes and other risk factors. $\mathrm{ECOH}$ provides free medicines to those who have prescriptions from doctors. Community-level campaigns have been organised to inform the people of the village about NCDs and related risk factors. Health assistants of $\mathrm{ECOH}$ visited all households to select eligible subjects but no more than three recall visits were done.

ECOH conducted geographic surveillance to identify and compile a complete list of households with demographic information of residents. As of 2015, the village had 1036 households. Residents aged $\geq 18$ years living in the village were the target population for this study. In total there were 4871 adults aged $\geq 18$ years ( 2520 men and 2351 women). However, 4414 residents (2202 men and 2212 women) were living in the village permanently. The remaining 457 residents lived in either urban areas or outside the country to earn their livelihoods and occasionally visited the village. Therefore, permanent residents aged $\geq 18$ years were considered eligible for the survey. Pregnant women were excluded.

\section{Patient and public involvement}

These data were collected as part of routine surveillance conducted by ECOH, which is managed and funded by the local community. Patients routinely attend health fairs and obtain free healthcare from ECOH. There was no patient or public involvement in the interpretation of analytic results.

\section{Survey instrument}

We administered a structured questionnaire to assess basic demographics and physical measurements of each participant. The questionnaire was administered in Bengali. We obtained details on household size and composition from the head of each household. Each participant provided information on tobacco use, salt intake, health history including history of diabetes, hypertension, stroke, heart disease and chronic respiratory illness, and physical measurements including blood pressure. History of hypertension was assessed using the following questions: (1) have you ever been diagnosed with hypertension by a healthcare provider?; (2) if yes, are you receiving treatment for the condition?; and (3) if yes, where are you receiving your treatment? Treatment history of participants was confirmed by ECOH field workers through prescription and medical charts. Blood pressure was measured by calibrated aneroid sphygmomanometer by a trained field interviewer. Blood pressure measurements were consistently taken on the right arm at level of the heart and elbow-assisted while the participant was seated. After a test run, the first measurement was performed after $5 \mathrm{~min}$ of rest on the right arm. After $3 \mathrm{~min}$, the second measurement was taken. The Korotkoff phase I (beginning of the sound) and the phase $\mathrm{V}$ of Korotkoff (disappearance of the sound) was recorded as systolic and diastolic blood, respectively. The mean of these two blood pressure readings was used as the final blood pressure for each participant.

\section{Outcome definition}

Our primary outcomes of interest were prevalence of hypertension and of prehypertension. We used the WHO guidelines diagnostic criteria to define hypertension. An individual was considered to have hypertension if systolic blood pressure (SBP) was $\geq 140 \mathrm{~mm} \mathrm{Hg}$ and/or, diastolic blood pressure (DBP) $\geq 90 \mathrm{~mm} \mathrm{Hg}$ and/or currently taking any-hypertensive medication based on self-report. 
Prehypertension was defined as SBP $\geq 120 \mathrm{~mm} \mathrm{Hg}$ but $<140 \mathrm{~mm} \mathrm{Hg}$ and/or DBP $\geq 80 \mathrm{~mm} \mathrm{Hg}$ but $<90 \mathrm{~mm} \mathrm{Hg}$ and not taking antihypertensive medication at the time of the survey.

\section{Covariates}

The following variables were used as risk factors: sex, age, education, occupation, body mass index (BMI), diabetes and tobacco use. Education was categorised into five groups: no education, less than primary (completed sgrade 4), primary school (completed grade 5), secondary school (completed grade 10) and higher secondary and above (completed $\geq$ grade 12). Occupation was categorised into five groups for analysis. These groups included: professional employment (government employee, nongovernment employee, business owner, farmer, agricultural worker and other self-employed), unemployed or retired, industrial worker or day labourer, housemaker and other (beggar, rickshaw puller, cook, carpenter, tailor, security guard, migrant workers and fishermen). Using height $(\mathrm{cm})$ and weight $(\mathrm{kg})$ measurements, we calculated BMI (height/weight ${ }^{2}$ and categorised these measurements as follows: underweight $(\leq 18.50)$, normal (18.6-25), overweight (25.1-30) and obese (>30). Participants were asked if they added any additional teaspoons of salt to their food during their meals. Added salt intake was categorised based on the number of tablespoons and the assumption that one tablespoon was equivalent to 5 g. Hyperglycaemia was defined based on a random blood glucose measured of 11.1 or above and/or self-report of taking diabetes medication. We categorised participants as tobacco users if they either smoked cigarettes, cigars or pipes, or if they used smokeless tobacco products such as zarda, sadapata, gul and/or snuff. We defined past tobacco users as respondents who were ever users of tobacco; however, currently do not use tobacco products.

\section{Data analysis}

Sociodemographic variables were presented with median (IQR) for continuous variables and with proportion for categorical variables. The overall, sex-specific, age-specific by sex and area-specific prevalence of hypertension were calculated. For bivariate analyses, study participants were divided by sex and into five age groups (18-29, 30-44, $45-59$ and $60+$ years). A $\chi^{2}$ test was performed to assess proportional differences in hypertension and treatment patterns across select categorical variables.

Adjusted and unadjusted Poisson regression using robust estimation of standard errors analyses were performed to identify determinants of prehypertension and hypertension. ${ }^{15-17}$ Potential determinants were assessed using bivariate Poisson regression analysis; an arbitrary $p$ value of $<0.10$ was used as criteria to include the variable in the multivariable Poisson regression model. For multivariable Poisson regression models, crude prevalence ratios, adjusted prevalence ratios (aPR) and 95\% CIs for each independent variable were calculated, $\mathrm{p}<0.05$ was used as the level of significance. Collinearity was assessed using the variance inflation factor to ensure a strong linear relationship among independent variables included in the model was not present. The outcome variable of the model to identify determinants for hypertension was coded as ' 1 ' if the participant was found to be hypertensive based on the definition described above and the rest were coded as ' 0 '. To identify determinants of prehypertension, we excluded those with existing hypertension at study measurement from the binary dependent variable of prehypertension. Accordingly, the outcome variable was coded as ' 1 ' if the participant was found to be prehypertensive and the rest were coded as ' 0 '. All statistical procedures were performed using Stata/SE V.15.1 (StataCorp LP) software package.

\section{RESULTS}

\section{Background characteristics}

Overall, out of 1036 households in the sampling frame, at least one participant from 866 households agreed to participate leading to an $83.6 \%$ response rate by household. On an individual level, 58.9\% (2600/4414) of village residents participated in our survey. Per household, there were an average 3.0 participants (95\% CI 2.89 to 3.11 ). In our sample, there were 1205 (46.4\%) men and 1395 $(53.7 \%)$ female respondents (table 1). The age of our participants ranged from 18 to 85 years. The mean age and education level of participants were $41.6(\mathrm{SD}=17.8)$ years and $4.9(\mathrm{SD}=4.6)$ years, respectively. On average, men were more educated then women, with $15.9 \%$ men pursuing above secondary education compared with $6.3 \%$ women. About one-third of men were employed as either an industrial worker/day labourer (38.3\%) or professional employment (39.3\%), and the majority of women were either a housewife $(87.2 \%)$ or unemployed $(11.9 \%)$. Smoking habits varied by sex: $99 \%$ of women reported to have never used smoking tobacco such as cigarettes; however, $51.3 \%$ of men either currently or previously used smoking tobacco. More women reported to currently use smokeless tobacco compared with men (31.8\% vs $21.4 \%)$. More women were overweight or obese than men (15.8\% vs $7.6 \%)$. Additionally, more women were categorised as hyperglycaemic compared with men $(3.2 \%$ vs $2.2 \%)$. Figure 1 provides a distribution of SBP and DBP by age group and sex.

\section{Prevalence and predictors of hypertension}

Overall, the prevalence of hypertension among our population of rural adults aged $\geq 18$ years was $6.9 \%$ (95\% CI 5.9 to 7.9). The prevalence of hypertension was significantly higher among women $(8.9 \%, 95 \%$ CI 7.4 to 10.5$)$ than men $(4.5 \%, 95 \%$ CI 3.4 to 5.8$)\left(\chi^{2} \mathrm{p} \leq 0.001\right)$. Additionally, the prevalence of hypertension increased with age among both men and women $(\mathrm{p}<0.001)$, with the highest prevalence of hypertension among women aged 60 years and above $(21.3 \%, 95 \%$ CI 16.6 to 26.7$)$ (figure 2). For comparability to prior studies, we report the prevalence 
Table 1 Background characteristics of participants of rural Ekhlaspur, Bangladesh $(n=2600)$

\begin{tabular}{|c|c|c|c|c|c|c|c|}
\hline \multirow[b]{2}{*}{ Characteristic } & \multicolumn{2}{|c|}{ Total $(n=2600)$} & \multicolumn{2}{|c|}{ Women ( $n=1395)$} & \multicolumn{2}{|c|}{ Men (n=1205) } & \multirow[b]{2}{*}{ P value ${ }^{\star}$} \\
\hline & $\mathbf{n}$ & $\%$ & $\mathbf{n}$ & $\%$ & $\mathbf{n}$ & $\%$ & \\
\hline \multicolumn{8}{|l|}{ Age (years) } \\
\hline 18-29 & 829 & 31.9 & 444 & 31.8 & 385 & 31.9 & 0.81 \\
\hline $30-44$ & 717 & 27.6 & 390 & 27.9 & 327 & 27.1 & \\
\hline $45-59$ & 530 & 20.4 & 289 & 20.7 & 241 & 20.0 & \\
\hline$\geq 60$ & 524 & 20.2 & 272 & 19.5 & 252 & 20.9 & \\
\hline Mean (SD) & \multicolumn{2}{|c|}{$41.6(17.8)$} & \multicolumn{2}{|c|}{$41.3(17.7)$} & \multicolumn{2}{|c|}{$41.9(17.9)$} & \\
\hline \multicolumn{7}{|l|}{ Educational status } & $<0.001$ \\
\hline No education & 825 & 31.7 & 463 & 33.2 & 362 & 30.0 & \\
\hline Primary education & 680 & 26.2 & 386 & 27.7 & 294 & 24.4 & \\
\hline Secondary education & 816 & 31.4 & 458 & 32.8 & 358 & 29.7 & \\
\hline Above secondary education & 279 & 10.7 & 88 & 6.3 & 191 & 15.9 & \\
\hline Mean (SD) & \multicolumn{2}{|c|}{$4.9(4.6)$} & \multicolumn{2}{|c|}{$4.5(4.1)$} & \multicolumn{2}{|c|}{$5.5(5.1)$} & \\
\hline \multicolumn{7}{|l|}{ Occupation } & $<0.001$ \\
\hline Professional employment† & 485 & 18.7 & 11 & 0.8 & 474 & 39.3 & \\
\hline Unemployed/retired & 312 & 12 & 166 & 11.9 & 146 & 12.1 & \\
\hline Industrial worker/day labourer & 463 & 17.8 & 1 & 0.1 & 462 & 38.3 & \\
\hline Homemaker/other $\ddagger$ & 1340 & 51.5 & 1217 & 87.2 & 123 & 10.2 & \\
\hline \multicolumn{7}{|l|}{ Smoking tobacco use } & $<0.001$ \\
\hline Never & 1975 & 75.9 & 1389 & 99.6 & 586 & 48.6 & \\
\hline Current use & 498 & 19.2 & 1 & 0.1 & 497 & 41.2 & \\
\hline Past use & 127 & 4.9 & 5 & 0.4 & 122 & 10.1 & \\
\hline \multicolumn{7}{|l|}{ Smokeless tobacco use } & $<0.001$ \\
\hline Never & 1804 & 69.4 & 913 & 65.5 & 891 & 73.9 & \\
\hline Current use & 702 & 27.0 & 444 & 31.8 & 258 & 21.4 & \\
\hline Past use & 94 & 3.6 & 38 & 2.7 & 56 & 4.7 & \\
\hline \multicolumn{7}{|l|}{ Added salt intake during meal } & 0.084 \\
\hline None & 256 & 9.9 & 134 & 9.6 & 122 & 10.1 & \\
\hline Less than $5 \mathrm{~g}$ (one teaspoon) & 1451 & 55.8 & 755 & 54.1 & 696 & 57.8 & \\
\hline Five grams and above & 893 & 34.3 & 506 & 36.3 & 387 & 32.1 & \\
\hline \multicolumn{8}{|l|}{ Body mass index§ } \\
\hline Underweight (<18.5) & 251 & 9.7 & 184 & 13.2 & 67 & 5.6 & $<0.001$ \\
\hline Normal (18.6-25) & 2035 & 78.3 & 989 & 70.9 & 1046 & 86.8 & \\
\hline Overweight (25.1-30) & 277 & 10.7 & 195 & 13.9 & 82 & 6.8 & \\
\hline Obese $(>30)$ & 37 & 1.4 & 27 & 1.9 & 10 & 0.8 & \\
\hline Capillary blood glucose level & & & & & & & 0.121 \\
\hline Normal & 2470 & 97.3 & 1306 & 96.8 & 1164 & 97.8 & \\
\hline Hyperglycaemic & 69 & 2.7 & 43 & 3.2 & 12 & 2.2 & \\
\hline History of stroke & 9 & 0.4 & 4 & 0.3 & 5 & 0.4 & - \\
\hline History of heart disease & 8 & 0.3 & 3 & 0.2 & 5 & 0.4 & \\
\hline
\end{tabular}

${ }^{*}$ Fisher's exact test $p$ value to identify differences between men and women surveyed.

†Professional occupation includes: government employee, non-government employee, business owner.

$\ddagger$ Other occupation includes: self-employed, home maker, student and other.

§Body mass index calculated by weight in kilogram divided by height in metre squared.

ףHyperglycaemic was defined as a random capillary blood glucose level greater than or equal to $11.1 \mathrm{mmol} / \mathrm{L}$ or self-reported diabetes medication use. 

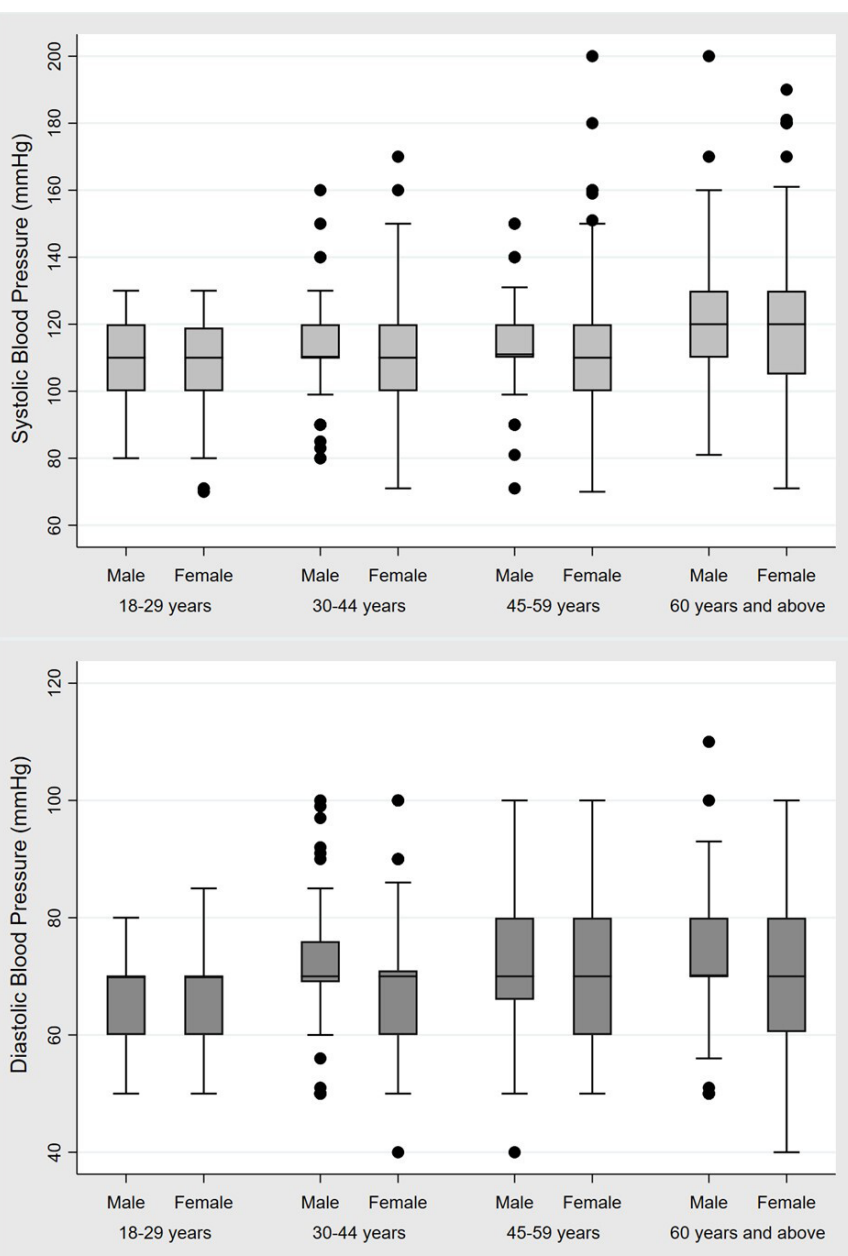

Figure 1 Distribution of systolic and diastolic blood pressure by age group and sex among rural adults in Bangladesh.

of hypertension if restricted to those aged $\geq 25$ years $(8.5 \%)$ and $\geq 35$ years $(11.3 \%)$.

Among women, the prevalence of hypertension decreased as education level increased (12.3\%: no education to $2.3 \%$ above secondary education); however, among men the prevalence of hypertension increased as education level increased (3.6\%: no education to $7.9 \%$ : above secondary education) (table 2). Among overweight and obese participants, the prevalence of hypertension was significantly higher than among those with normal BMI, particularly among men $(60 \%$ of obese men had hypertension). Additionally, the prevalence of hypertension was significantly higher among those with hyperglycaemia or blood glucose levels approaching the diabetic limit (>11.1 mmol/L) (table 2).

Table 3 presents the results of multivariable Poisson regression with robust variance analyses to identify determinants of hypertension. SDeterminants of hypertension differed among men and women. Among women, those of older age, both underweight and overweight/obesity BMI, and with hyperglycaemia were more likely to have hypertension. When compared with women with normal BMI, women categorised as underweight or a BMI of
- Women $(n=1395)$

Men $(n=1205)$

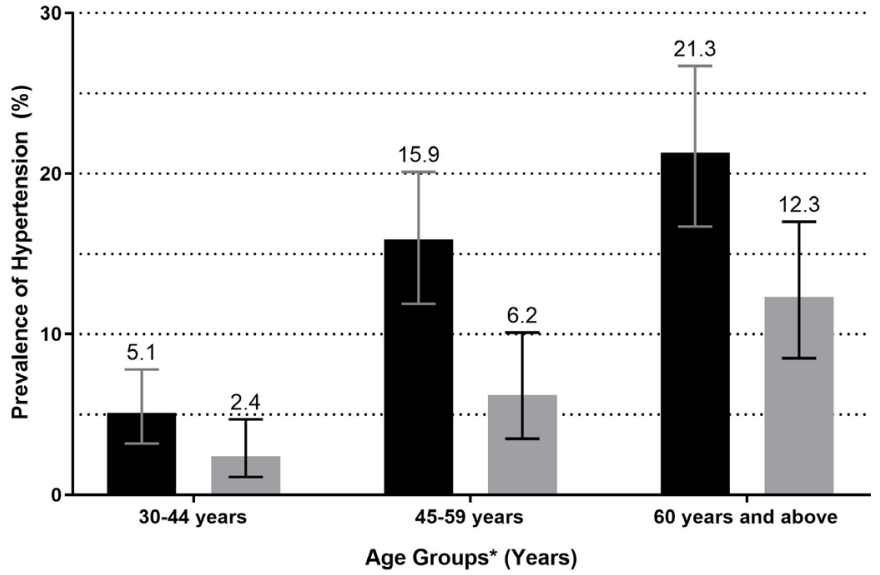

Figure 2 Prevalence of hypertension stratified by age group and sex among rural adults in Bangladesh. *Age group 18-29 years was not included as prevalence of hypertension was $0 \%$ for both men and women.

18.5 and below had 1.6 times the prevalence of hypertension (95\% CI 1.1 to 2.5). Additionally, women who were overweight (aPR: 2.3, 95\% CI 1.5 to 3.5) and obese (aPR: $4.9,95 \%$ CI 2.4 to 10.0 ) had a significantly higher prevalence of hypertension when compared with women with normal BMI. After adjustment, educational status no longer appeared to have a significant relationship with hypertension prevalence although the crude analysis revealed a protective effect of higher education. Among men, those of older age, increasing educational level, being overweight and obese, and with hyperglycaemia were more likely to have hypertension. Unlike in women, among men with an educational level above secondary education, the prevalence of hypertension was 3.8 times that of men with no formal education (aPR: 3.8, 95\% CI 1.8 to 8.2 ). Hyperglycaemia was a significant determinant of hypertension among both women (aPR: $2.5,95 \% \mathrm{CI}$ 1.4 to 4.4 ) and men (aPR: $3.8,95 \%$ CI 2.0 to 7.0 ).

\section{Awareness and treatment of hypertension}

Overall, among those with hypertension, $58 \%$ were aware of their diagnosis (figure 3). The proportion of those aware of their hypertension diagnosis was higher among men $(72 \%)$ then women $(52 \%)$. When assessed by age group, the proportion of women who were aware of their diagnosis decreased with increasing age, dropping from $55 \%$ among those aged 30-44 years to $46.5 \%$ among women aged 60 years and above. Among those who were aware of their hypertension diagnosis $(n=105), 99.1 \%$ of participants $(n=104)$ self-reported to take antihypertensive medication. Among those who are taking medication to control their hypertension, $55.2 \%$ had normal blood pressure (SBP: $<140 \mathrm{~mm} \mathrm{Hg}$ and DBP: $<90 \mathrm{~mm} \mathrm{Hg}$ ). The proportion of participants with controlled hypertension did not significantly differ by sex (men: $58.9 \%$, women: $\left.53.0 \%, \chi^{2} \mathrm{p}=0.55\right)$. 
Table 2 Prevalence of hypertension by sex and select demographic variables among rural Bangladeshi adults

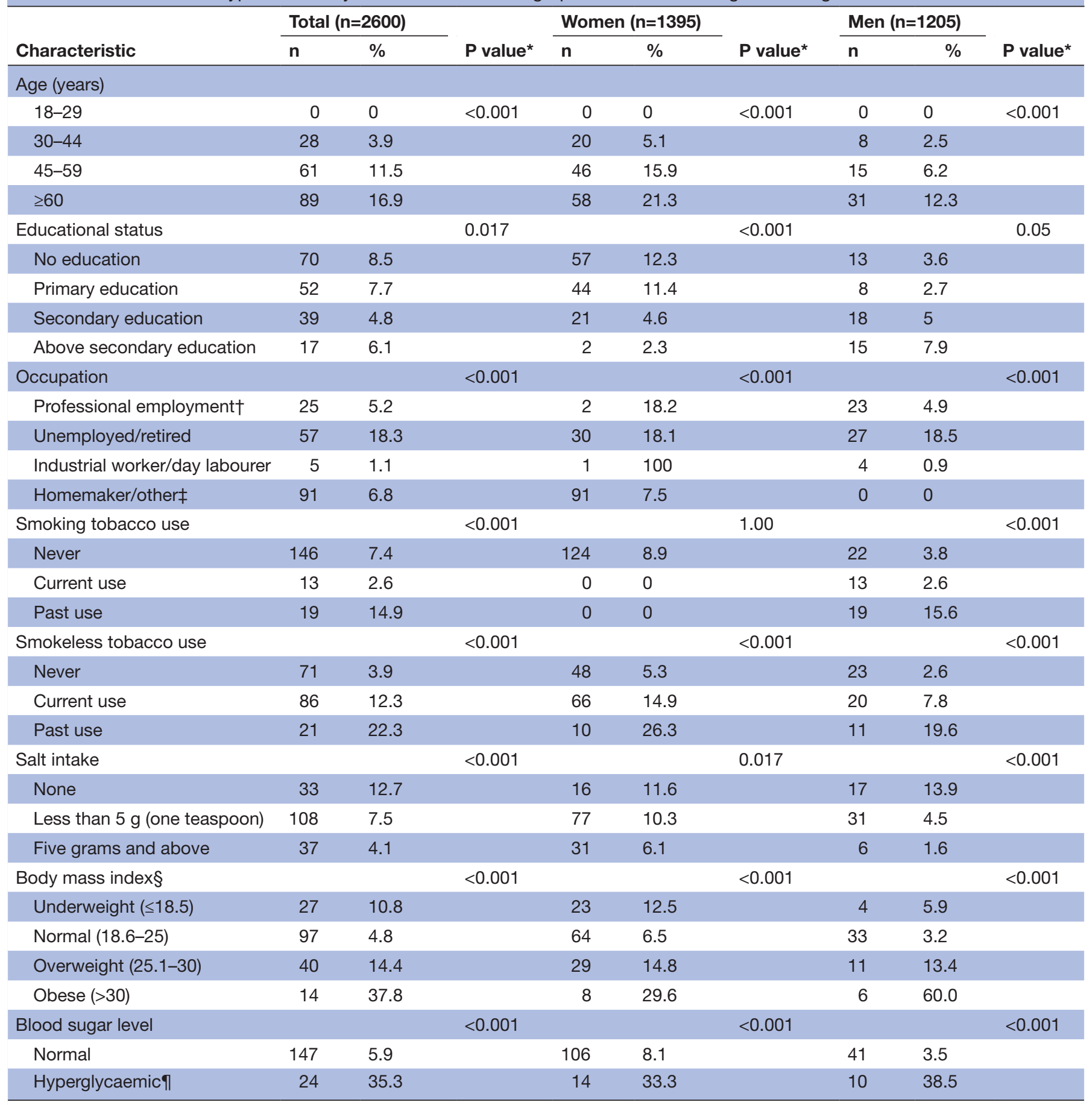

*Fisher's exact test $\mathrm{p}$ value for trend.

†Professional occupation includes: government employee, non-government employee, business owner. fOther occupation includes: self-employed, home maker, student, and other.

$\S$ Body mass index calculated by weight in kilogram divided by height in metre squared.

ПDiabetes was defined as a random capillary blood glucose level greater than or equal to $11.1 \mathrm{mmol} / \mathrm{L}$ or self-reported diabetes medication use.

Prevalence and predictors of prehypertension

The prevalence of prehypertension among our population of rural adults was $37.7 \%$ (95\% CI 35.7 to 39.6). Overall, the prevalence of prehypertension was higher among men (41.4\%, 95\% CI 38.6 to 44.3$)$ than women
(34.2\%, 95\% CI 31.6 to 36.9$)$ (table 4). This sex difference in prevalence of prehypertension was consistent across all age groups (figure 4). The highest prevalence of prehypertension was observed among men and women aged 60 years and above $(57.9 \%, 50 \%$, respectively) (figure 4$)$. 
Table 3 Determinants of hypertension by sex among rural Ekhlaspur, Bangladesh $(n=2600)$

\begin{tabular}{|c|c|c|c|c|c|c|}
\hline \multirow[b]{2}{*}{ Characteristic } & \multicolumn{2}{|l|}{ Total $(n=2600)$} & \multicolumn{2}{|l|}{ Women $(n=1395)$} & \multicolumn{2}{|l|}{ Men $(n=1205)$} \\
\hline & $\begin{array}{l}\text { Crude PR (95\% } \\
\text { Cl) }\end{array}$ & $\begin{array}{l}\text { Adjusted PR } \\
(95 \% \mathrm{Cl})\end{array}$ & $\begin{array}{l}\text { Crude PR (95\% } \\
\text { Cl) }\end{array}$ & $\begin{array}{l}\text { Adjusted PR } \\
(95 \% \mathrm{Cl})\end{array}$ & Crude PR $(95 \%$ Cl) & $\begin{array}{l}\text { Adjusted PR } \\
(95 \% \mathrm{Cl})\end{array}$ \\
\hline \multicolumn{7}{|l|}{ Sex } \\
\hline Men & Ref. & Ref. & - & - & - & - \\
\hline Women & $2.0(1.5$ to 2.7$)$ & 2.2 (1.6 to 3.0$)$ & - & - & - & - \\
\hline \multicolumn{7}{|l|}{ Age (years) } \\
\hline $\begin{array}{l}55 \text { years and } \\
\text { above }\end{array}$ & 4.9 (3.7 to 6.6$)$ & 5.0 (3.3 to 7.6$)$ & 4.5 (3.2 to 6.4$)$ & 3.8 (2.3 to 6.2 ) & 6.8 (3.8 to 12.1$)$ & 6.8 (3.2 to 14.2$)$ \\
\hline \multicolumn{7}{|l|}{ Educational status } \\
\hline No education & Ref. & Ref. & Ref. & Ref. & Ref. & Ref. \\
\hline $\begin{array}{l}\text { Above secondary } \\
\text { education }\end{array}$ & 0.7 (0.4 to 1.2$)$ & 2.4 (1.4 to 4.0$)$ & 0.2 (0.0 to 0.7 ) & 0.6 (0.1 to 2.4$)$ & 2.2 (1.1 to 4.5$)$ & 3.8 (1.8 to 8.2 ) \\
\hline \multicolumn{7}{|l|}{ Ever tobacco use* } \\
\hline Never & Ref. & Ref. & Ref. & Ref. & Ref. & Ref. \\
\hline $\begin{array}{l}\text { Currently or in the } \\
\text { past }\end{array}$ & 2.3 (1.7 to 3.2 ) & 1.3 (0.9 to 2.0$)$ & 3.0 (2.1 to 4.2 ) & 1.3 (0.79 to 2.0$)$ & 2.3 (1.2 to 4.1$)$ & 1.0 (0.5 to 2.2$)$ \\
\hline \multicolumn{7}{|l|}{ Body mass index†† } \\
\hline $\begin{array}{l}\text { Underweight } \\
(\leq 18.5)\end{array}$ & 2.3 (1.5 to 3.4 ) & 1.7 (1.1 to 2.5$)$ & 1.9 (1.2 to 3.0$)$ & 1.6 (1.1 to 2.5$)$ & 1.9 (0.7 to 5.2$)$ & $1.9(0.7$ to 5.2$)$ \\
\hline Normal (18.6-25) & Ref. & Ref. & Ref. & Ref. & Ref. & Ref. \\
\hline
\end{tabular}

*Ever tobacco use includes ever smokeless or smoking tobacco use.

†Body mass index was calculated by weight in kilogram divided by height in metre squared and included in the model as a continuous variable. †Hyperglycaemia was defined as a random capillary blood glucose level greater than or equal to $11.1 \mathrm{mmol} / \mathrm{L}$ or self-reported diabetes medication use.

PR, prevalence ratio.

Table 4 presents the results of multivariable Poisson regression with robust variance analyses to identify determinants of prehypertension. Among both women, determinants of prehypertension included older age $(\geq 45$ years) and being overweight or obese. Among women who were aged 45-59 years the prevalence of hypertension was 1.4 times that of the prevalence among women aged 18-29 years. Additionally, the prevalence of women aged 60 years and above was 2.3 times that of women aged 18-29 years. Women who were obese had two times the prevalence of hypertension compared with women with a normal BMI. Similar determinants were identified among men: men who were obese had 1.9 times the prevalence of men with a normal BMI. Increasing age among men also led to an increase in hypertension prevalence.
Hyperglycaemia was not a significant determinant of prehypertension among men or women (table 4).

\section{DISCUSSION}

In this study of adults aged $\geq 18$ years in one rural area of Bangladesh, the prevalence of hypertension prevalence was significantly higher among women compared with men. The determinants of hypertension were consistent across sex excluding educational level; as educational level increased, the prevalence of hypertension increased among men whereas among women hypertension prevalence decreased, indicating a potential protective effect. Women were less likely to be aware they had hypertension compared with men, particularly older women aged $\geq 60$ 


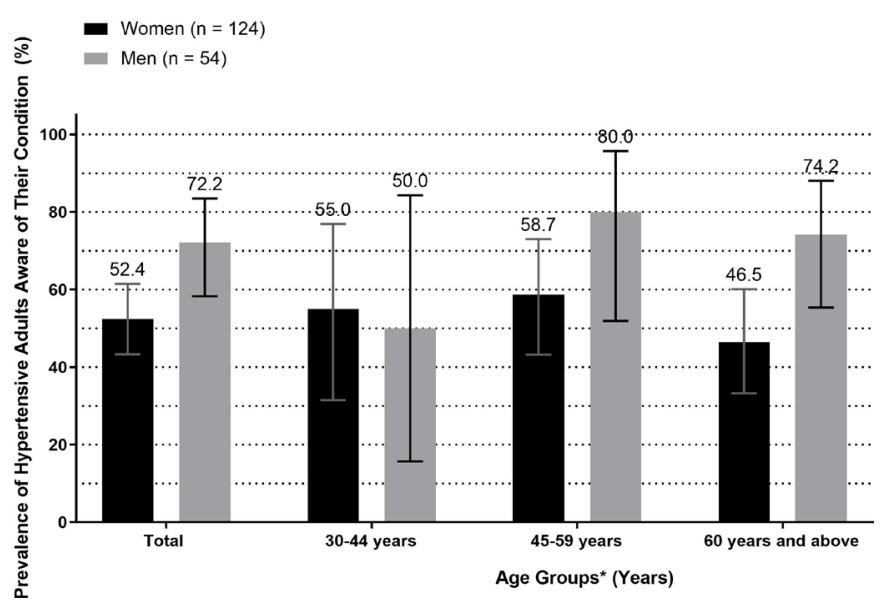

Figure 3 Prevalence of awareness of hypertension diagnosis stratified by age group and sex among rural adults in Bangladesh. *Age group 18-29 years was not included as prevalence of hypertension was $0 \%$ for both men and women.

years. Among adults who were aware of their condition, we did not find any sex differences in antihypertensive medication use as almost $100 \%$ of adults who were previously diagnosed with hypertension self-reported to take antihypertensive medication. Findings from this survey may highlight the need for sex-specific tailored interventions. Additionally, results from this analysis may underscore the importance of identifying high-risk groups in rural areas, particularly elderly women as their prevalence of hypertension rivals that of urban residents in Bangladesh.

In our study, the overall prevalence of hypertension was $6.9 \%$, which is lower than prior studies conducted in Bangladesh. Nationally representative data, including both urban and rural residents, collected in 2010 among adults $\geq 25$ years estimated the prevalence of hypertension and prehypertension was $20 \%$ and $43 \%$, respectively. ${ }^{6}$ Similar to our study's findings, the prevalence of hypertension among rural women (18.2\%) was slightly higher than men $(17.6 \%)$. Another nationally representative analysis conducted in 2011 among adults $\geq 35$ years found the age-standardised prevalence of hypertension and prehypertension was $24.4 \%$ and $27.1 \%$; the odds of having hypertension were higher among women compared with men $^{18}$ in both urban and rural regions. ${ }^{19}$ In one study conducted in rural Bangladesh, the prevalence of hypertension was $16 \%$ and factors such as increasing age and higher BMI was positively associated with hypertension. ${ }^{10}$ Although they found no difference in prevalence of hypertension by sex, the prevalence of prehypertension was higher among men (33.6\%) than women (30.6\%), which is similar to our findings. Another study conducted in a different rural area of Bangladesh identified a strikingly high prevalence of hypertension among over 3000 adults aged $\geq 30$ years across both sex groups of $40 \%$ (95\% CI $38 \%$ to $42 \%) .{ }^{20}$

Hypertension prevalence in our study may be lower than previously documented due to two reasons. First, our cohort was younger and included adults aged $\geq 18$ years. We found hypertension prevalence among our younger participants (18-29 years) to be $0 \%$, although the prevalence of prehypertension was almost $30 \%$ in both sexes. Second, the lower hypertension prevalence may be attributable to various public health interventions promoted by ECOH over the past several decades to lower and control blood pressure of Ekhlaspur residents. Through these public health interventions, residents of Ekhlaspur have been advised to be more physically active, avoid tobacco and alcohol products, and reduce dietary salt intake. ECOH has provided chronic disease preventive and treatment services for several years at low or free cost. Additionally, the clinic provides patients with counselling on lifestyle changes and provides antihypertensive medications free of charge. Free and low-cost preventive services are not widespread in rural areas of Bangladesh. In 2014 , it was estimated that only $16 \%$ of healthcare facilities across the country (ie, hospitals, community clinics) have the capacity to diagnose, prescribe treatment for and manage patients with hypertension. ${ }^{21}$ In fact, only $10 \%$ of community clinics and maternal and child welfare centres, and $17 \%$ of union level facilities, which are the most accessible providers in rural areas, provided any cardiovascular services, and the services at these facilities are limited to the measurement of blood pressure or referrals. ${ }^{21}$ Additionally, among facilities with the capacity to offer services for hypertension management, less than one-third had essential CVD medicines readily available on-site for patients. ${ }^{21}$ Prior studies have shown that barriers to seeking hypertension treatment in Bangladesh include inadequate availability of services, poor quality of existing facilities, shortage of medicine supplies, long distance to healthcare facilities and cost of continued treatment once diagnosed. ${ }^{22}{ }^{23} \mathrm{ECOH}$ has been able to address these barriers by providing consistent care to the residents of Ekhlaspur and at free or low cost. As Bangladesh moves towards implementing universal healthcare, ${ }^{24}$ efforts should be focused on establishing clinics particularly in rural areas to make healthcare accessible and to support the continuity of care.

Our study demonstrates important sex differences in both prevalence, determinants, and awareness of hypertension in rural Bangladesh. Hypertension prevalence among women $(8.9 \%)$ was significantly higher than among men $(4.5 \%, \mathrm{p}<0.001)$. Additionally, we found that as age increases, the difference in prevalence by sex also increases drastically; among adults aged $\geq 60$ years the difference in prevalence of hypertension is almost double (21.3\% among women vs $12.3 \%$ ) among men. Moreover, men were more likely to be aware of having hypertension than women, leaving almost half of women with hypertension unaware and untreated for their condition. However, when adults were aware of their condition there were no sex differences in hypertension treatment or medication use. Efforts to ensure women have equal access to preventive care as men in rural areas of Bangladesh should be prioritised. 
Table 4 Determinants of prehypertension by sex among rural Ekhlaspur, Bangladesh $(\mathrm{n}=2422)$

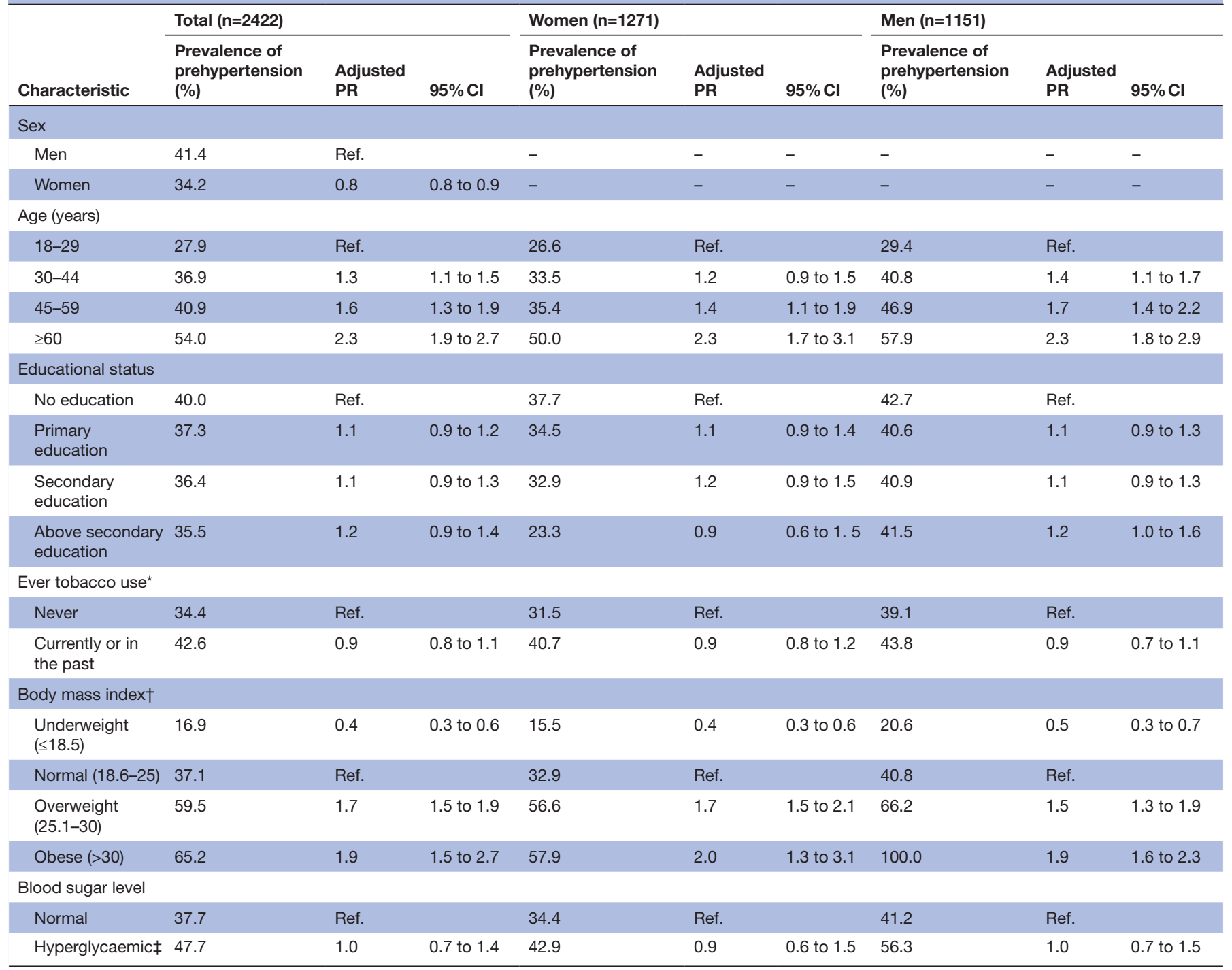

*Ever tobacco use includes ever smokeless or smoking tobacco use.

†Body mass index calculated by weight in kilogram divided by height in metre squared.

$\ddagger$ Hyperglycaemia was defined as a random capillary blood glucose level greater than or equal to $11.1 \mathrm{mmol} / \mathrm{L}$ or self-reported diabetes medication use.

PR, prevalence ratio; Ref, reference.
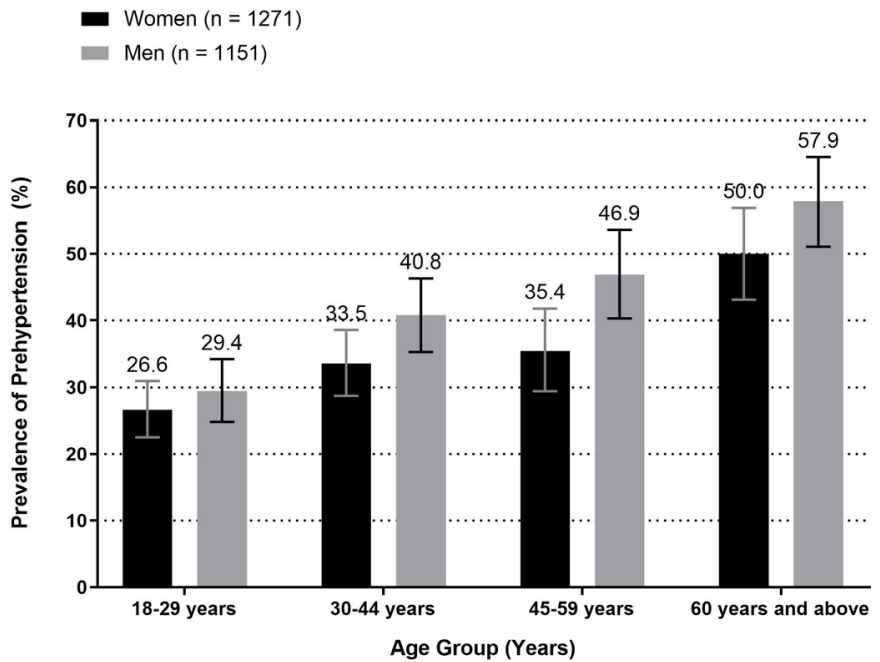

Figure 4 Prevalence of prehypertension stratified by age group and sex among rural adults in Bangladesh.
In our analysis, we found that female sex, older age, higher education, high BMI and blood glucose levels approaching the diabetic range $(\geq 11.1)$ were determinants of hypertension, which is similar to prior nationally representative studies conducted in Bangladesh. ${ }^{13} 2526$ These determinants were consistent across sex groups, excluding educational status. Among men, higher education led to an increase in hypertension prevalence when compared with no education. However, among women, higher education appeared to have a protective effect when compared with no education although not statistically significant after adjustment. Higher educational attainment among women may be lead to employment, higher physical activity and active commuting, which have been shown to reduce sedentary behaviour among Bangladeshi women. ${ }^{27}$

This study has several strengths. First, we present novel prevalence data on hypertension and prehypertension 
as we included adults aged 18 years and above, whereas prior studies have started their cohorts at older ages. As such, these may be useful towards informing our progress towards NCD control as defined by the indicators included in the WHO's Global Monitoring Framework. ${ }^{28}$ Additionally, we used WHO-recommended standardised methods to measure BP among our study population to limit the potential for measurement error. There are several limitations to be considered when interpreting our results. Our study is limited to one rural area of Bangladesh and may not be reflective of other areas of the country. Prior to this survey, communitylevel campaigns took place to educate the adults on NCD prevention and lifestyle changes that may reduce their risk of developing chronic diseases. As such, they were generally more educated about public health interventions, which may limit the generalisability of our findings. Self-reported medication use may be subject to social desirability bias as participants are in regular contact with ECOH staff members through community campaigns and prior surveillance efforts. We were unable to measure important risk factors of hypertension such as diet, physical activity, waist circumference, family history of CVD and blood lipid levels. Additionally, we did not repeat blood pressure readings after 4 weeks to confirm a diagnosis of hypertension. Finally, due to the cross-sectional nature of our study design, we were unable to assess temporality of our risk factors or establish any causal relationship with our outcomes of interest.

Published in 2013, the Guidelines for Management of Hypertension in Bangladesh largely recommend and focus on lifestyle measures to reduce the risk of hypertension in adults. ${ }^{8}$ This is because Bangladesh is a low resource setting with limited availability of trained healthcare providers and treatment, particularly in rural areas. Affordability of treatment is an important factor all providers should consider, since costs may impact adherence and continuity of care. In our setting, we observe a low prevalence of hypertension, particularly among younger groups, and also hyperglycaemic. We believe this low prevalence is due to the availability and access to preventive healthcare, such as physical activity and tobacco cessation campaigns. We recommend that other rural areas follow the national guidelines for hypertension management, and promote similar lifestyle changes, to achieve similar burden reduction. Interestingly, we observed that normotensives had higher added salt intake $(90.6 \%)$ compared with hypertensive adults $(81.5 \%)$. This may be due to an ongoing dietary salt reduction campaign in Ekhlaspur village focused on high-risk patients, including hypertensive adults. Clinical based data from ECOH have clearly demonstrated a sharp decline of added salt intake among those who have hypertension, dropping from $73 \%$ at enrolment to $13 \%$ after about 5 months, based on selfreport ${ }^{29}$ Similarly, we observed a high proportion of hypertensive participants who previously used tobacco. Patients of ECOH with hypertension have been counselled on the harms of tobacco use, both smokeless and smoking, and as such the majority reported to use either tobacco form in the past.

\section{CONCLUSION}

In conclusion, our sex-disaggregated analysis showed a higher burden of hypertension among women compared with men in a rural area of Bangladesh. Furthermore, we found that women were less likely to be have been previously diagnosed with hypertension compared with men and thus, more women had uncontrolled hypertension. The prevalence of prehypertension was higher among men than women. An alarmingly high proportion of those aged $18-29$ years had prehypertension (27.9\%). A preventive community-based approach with sex-tailored educational efforts should be directed to those with prehypertension, as they are at highest risk of developing hypertension. The primary healthcare system of Bangladesh is limited, particularly in rural areas, due to a shortage of trained healthcare providers including physicians and nurses. Efforts towards population-level prevention measures, specifically lifestyle changes, should be promoted and directed towards risk groups identified through this analysis, such as those who are overweight or obese.

\section{Twitter Jessica Yasmine Islam @jyislam}

Acknowledgements We gratefully acknowledge the management committees of Ekhlaspur Primary School, Ekhlaspur high school, Market committee, Motor Launch Station Shop Owners Committee, Union Council, Ibrahim Madrasha, village doctors of the area and government and non-government health workers. The management committee of ECOH, its health counsellors and field workers deserve special thanks.

Contributors JYI conceptualised the manuscript, guided data analysis, interpreted critically, wrote the manuscript; MMZ conceptualised the intervention, assisted with data analysis and manuscript development; JUA and SRC established methodologies, executed the campaign, supervised and monitored data collection, trained the health workers; TZ conducted clinical-based counselling, trained counsellors on counselling skills, reviewed literature and prepared citations; HK prepared questionnaires, maintained records, worked as a data manager. All authors have read and approved the submission.

Funding Data collection was conducted using ECOH's own funds generated by the local community as regular surveillance.

Disclaimer We did not receive any funding from external organisations to complete this work.

Competing interests None declared.

Patient consent for publication Not required.

Ethics approval To inform the community about this survey, ECOH management organised meetings and orientations with the community leaders, schools, and union council members. This survey is part of the community's initiative to monitor their health status and to detect any hypertension, diabetes and other risk factors. $\mathrm{ECOH}$ provides free medicines to those who have prescriptions from doctors. Community-level campaigns have been organised to inform the people of the village about NCDs and related risk factors. Health assistants of ECOH visited all households to select eligible subjects but no more than three recall visits were done. Ethical guidelines as outlined and approved by the Bangladesh Medical Research Council were followed throughout the study. Written informed consent was obtained from the respondents in Bengali to participate in this survey.

Provenance and peer review Not commissioned; externally peer reviewed.

Data availability statement Data are available upon reasonable request. Data are available upon reasonable request submitted to Dr Mostafa Zaman at mmostafazaman@gmail.com. 
Open access This is an open access article distributed in accordance with the Creative Commons Attribution Non Commercial (CC BY-NC 4.0) license, which permits others to distribute, remix, adapt, build upon this work non-commercially, and license their derivative works on different terms, provided the original work is properly cited, appropriate credit is given, any changes made indicated, and the use is non-commercial. See: http://creativecommons.org/licenses/by-nc/4.0/.

\section{ORCID iDs}

Jessica Yasmine Islam http://orcid.org/0000-0002-3690-3848

Hasanuzzaman Khan http://orcid.org/0000-0002-0993-5959

\section{REFERENCES}

1 WHO. A global brief on hypertension: silent killer, global public health crisis. Geneva, Switzerland: World Health Organization, 2013.

2 Lloyd-Sherlock P, Beard J, Minicuci N, et al. Hypertension among older adults in low- and middle-income countries: prevalence, awareness and control. Int J Epidemiol 2014;43:116-28.

3 Kearney PM, Whelton M, Reynolds K, et al. Global burden of hypertension: analysis of worldwide data. Lancet 2005;365:217-23.

4 Moniruzzaman TA, Rahman S. Prevalence of hypertension among the Bangladeshi adult population: a meta-analysis. Reg Health Forum 2013;17:15-19.

5 Zaman MM, Rouf MA. Prevalence of hypertension in a Bangladeshi adult population. J Hum Hypertens 1999;13:547-9.

6 Rahman M, Zaman MM, Islam JY, et al. Prevalence, treatment patterns, and risk factors of hypertension and pre-hypertension among Bangladeshi adults. J Hum Hypertens 2018;32:334-48.

7 Neupane D, McLachlan CS, Sharma R, et al. Prevalence of hypertension in member countries of South Asian association for regional cooperation (SAARC): systematic review and meta-analysis. Medicine 2014;93:e74.

8 National Guidelines for Management of Hypertension in Bangladesh. Dhaka, Bangladesh: WHO/SEARO/Country office for Bangladesh and DGHS, Ministry of health and family welfare, 2013.

9 Ahsan Karar Z, Alam N, Kim Streatfield P. Epidemiological transition in rural Bangladesh, 1986-2006. Glob Health Action 2009;2. doi:10.3402/gha.v2i0.1904. [Epub ahead of print: 19 Jun 2009].

10 Khanam MA, Lindeboom W, Razzaque A, et al. Prevalence and determinants of pre-hypertension and hypertension among the adults in rural Bangladesh: findings from a community-based study. BMC Public Health 2015;15:203.

11 Fottrell E, Ahmed N, Shaha SK, et al. Distribution of diabetes, hypertension and non-communicable disease risk factors among adults in rural Bangladesh: a cross-sectional survey. BMJ Glob Health 2018;3:e000787.

12 Biswas T, Townsend N, Islam MS, et al. Association between socioeconomic status and prevalence of non-communicable diseases risk factors and comorbidities in Bangladesh: findings from a nationwide cross-sectional survey. BMJ Open 2019;9:e025538.

13 Rahman M, Zaman MM, Islam JY, et al. Prevalence, treatment patterns, and risk factors of hypertension and pre-hypertension among Bangladeshi adults. J Hum Hypertens 2018;32:334-348.
14 Ekhlaspur center of health, 2018. Available: http://ecohbd.org/index. php [Accessed Jun 2018].

15 Coutinho LMS, Scazufca M, Menezes PR. Methods for estimating prevalence ratios in cross-sectional studies. Rev Saude Publica 2008;42:992-8.

16 Behrens T, Taeger D, Wellmann J, et al. Different methods to calculate effect estimates in cross-sectional studies. A comparison between prevalence odds ratio and prevalence ratio. Methods Inf Med 2004;43:505-9.

17 Barros AJD, Hirakata VN. Alternatives for logistic regression in crosssectional studies: an empirical comparison of models that directly estimate the prevalence ratio. BMC Med Res Methodol 2003;3:21.

18 Rahman MM, Gilmour S, Akter S, et al. Prevalence and control of hypertension in Bangladesh: a multilevel analysis of a nationwide population-based survey. J Hypertens 2015;33:465-72.

19 Kibria GMA, Swasey K, Das Gupta R, et al. Differences in prevalence and determinants of hypertension according to rural-urban place of residence among adults in Bangladesh. J Biosoc Sci 2018:1-13.

20 Islam FMA, Bhuiyan A, Chakrabarti R, et al. Undiagnosed hypertension in a rural district in Bangladesh: the Bangladesh population-based diabetes and eye study (BPDES). J Hum Hypertens 2016;30:252-9.

21 NIPORT. Bangladesh health facility survey 2014 Dhaka, Bangladesh: National Institute of population research and training (NIPORT), associates for community and population research (ACPR), and ICF international, 2016. Available: https://dhsprogram.com/pubs/pdf/ SPA23/SPA23.pdf accessed 03/15 2019

22 Legido-Quigley H, Naheed A, de Silva HA, et al. Patients' experiences on accessing health care services for management of hypertension in rural Bangladesh, Pakistan and Sri Lanka: a qualitative study. PLoS One 2019;14:e0211100.

23 Khatib R, Schwalm J-D, Yusuf S, et al. Patient and healthcare provider barriers to hypertension awareness, treatment and follow up: a systematic review and meta-analysis of qualitative and quantitative studies. PLoS One 2014;9:e84238.

24 Rahman MS, Rahman MM, Gilmour S, et al. Trends in, and projections of, indicators of universal health coverage in Bangladesh, 1995-2030: a Bayesian analysis of population-based household data. Lancet Glob Health 2018;6:e84-94.

25 Chowdhury MAB, Uddin MJ, Haque MR, et al. Hypertension among adults in Bangladesh: evidence from a national cross-sectional survey. BMC Cardiovasc Disord 2016;16:22.

26 Islam JY, Zaman MM, Haq SA, et al. Epidemiology of hypertension among Bangladeshi adults using the 2017 ACC/AHA hypertension clinical practice guidelines and joint National Committee 7 guidelines. J Hum Hypertens 2018;32:668-80.

27 Moniruzzaman M, Mostafa Zaman M, Islalm MS, et al. Physical activity levels in Bangladeshi adults: results from steps survey 2010. Public Health 2016;137:131-8.

28 Ncd global monitoring framework: World Health organization, 2017. Available: http://www.who.int/nmh/global_monitoring_framework/en/ [Accessed 29 Sep 2017].

29 Zaman MM, Ahmed J, Choudhury SR, et al. Hypertension clinic service is a good opportunity for tobacco cessation in Bangladeshi villagers. Cardiovascular Journal 2016;9:19-22. 